\section{Screening of celiac disease in patients with autoimmune thyroid disease from Southern Brazil}

\author{
Pesquisa de doença celíaca em pacientes com \\ doença autoimune de tireoide do sul do Brasil
}

Laila M. Teixeira', Renato Nisihara',3, Shirley Ramos da Rosa Utiyama ${ }^{3}$, Ricardo

S. de Bem ${ }^{4}$, Cristina Marcatto', Michelli Bertolazo33, Gisah A. de Carvalho'

\begin{abstract}
Objective: The objective of this study was to determine the prevalence of celiac disease (CD) in adults with autoimmune thyroid disease (ATD) from the endocrinology outpatient setting in a university hospital in Southern Brazil. Subjects and methods: From the years 2007 to 2011, 254 patients with ATD were enrolled consecutively, Grave's disease was diagnosed in $143(56.3 \%)$ and Hashimoto's thyroiditis in 111 (43.7\%) of them. All patients answered a questionnaire related to symptoms that could be associated with $C D$ and serum samples to screen for $\lg A$ anti-endomysial $($ EmA-lgA) were collected. EmA-lgA-positive patients were offered upper gastrointestinal endoscopy and biopsy of duodenum. Results: A total of 254 patients were included; 222 (87.4\%) female, mean age $45.4 \pm 13.43$ years (18 to 79 years). EmA-lgA was positive in seven patients $(2.7 \%$ ) and five done endoscopy with biopsy. Of these, three diagnosis of CD was confirmed (1.2\%). All the three patients with CD had higher EmA-IgA titration, were female and had Hashimoto's thyroiditis. Like other patients with ATD, CD patients had nonspecific gastrointestinal symptoms, such as heartburn and gastric distention. In our study, one in each 85 patients confirmed the diagnosis of CD. Conclusion: We found a prevalence of 1.2\% (1:85) of confirmed CD among Brazilian patients with ATD. Although some IgA-EmA positive patients had Graves' disease and one was male, all three patients with confirmed CD were female and had Hashimoto's thyroiditis. Arq Bras Endocrinol Metab. 2014;58(6):625-9
\end{abstract}

Keywords

Celiac disease; Hashimoto's disease; Graves' disease

\section{RESUMO}

Objetivo: O objetivo do presente estudo foi determinar a prevalência de doença celíaca (DC) em adultos com doenças autoimunes de tireoide (DAT) que foram atendidos em um serviço de endocrinologia de um hospital universitário do sul do Brasil. Sujeitos e métodos: Entre os anos de 2007 a 2011, 254 pacientes com DAT foram consecutivamente incluídos, sendo 143 (56,3\%) desses diagnosticados com doença de Graves e 111 (43,7\%) com doença de Hashimoto. Todos os pacientes responderam a um questionário relatando sintomas que poderiam ser associados com DC, e amostras de soro para a pesquisa de anticorpo antiendomisial (EmA-lgA) foram coletadas. Os pacientes com sorologia positiva foram encaminhados para endoscopia gastrointestinal com biópsia duodenal. Resultados: No total, 254 pacientes foram incluídos, sendo $222(87,4 \%)$ mulheres com média de idade $45,4 \pm 13,43$ anos (18 a 79 anos). EmA-lgA foi positivo em sete $(2,7 \%$ ) pacientes e cinco fizeram endoscopia com biópsia. Desses, três $(1,2 \%)$ tiveram o diagnóstico de DC confirmada. Todos os três pacientes com DC apresentaram altos títulos de EmA-lgA, eram mulheres e tinham doença de Hashimoto. Assim como outras pacientes com DAT, os pacientes celíacos tinham sintomas gastrointestinais inespecíficos, como queimação e distensão gástrica. Em nosso estudo, um em cada 85 pacientes com DAT tiveram o diagnóstico de DC confirmado. Conclusão: Em nosso estudo, foi observada prevalência de 1,2\% (1:85) de DC confirmada entre os pacientes com DAT, sendo todas mulheres e com doença de Hashimoto. Arq Bras Endocrinol Metab. 2014;58(6):625-9
${ }^{1}$ Endocrinology Service, Clinical Hospital, Federal University of Paraná (UFPR), Curitiba, PR, Brazil 2 University Positivo, Department of Medicine, Curitiba, PR, Brazil

${ }^{3}$ Laboratory of Immunopathology, Clinical Hospital, UFPR,

Curitiba, PR, Brazil

${ }^{4}$ Gastroenterology and Endoscopy Service, Clinical Hospital, UFPR, Curitiba, PR, Brazil
Correspondence to Renato Nisihara Rua João Azolin, 660 82040-015 - Curitiba, PR, Brazil renatonisihara@up.com.br

Received on Sept/19/2013 Accepted on Mar/21/2014

DOI: 10.1590/0004-2730000003003 


\section{INTRODUCTION}

$\mathrm{T}$ he most common autoimmune thyroid diseases (ATDs) are Hashimoto's thyroiditis and Graves' disease (1). The incidence of Hashimoto's thyroiditis is approximately 3.5 cases per 1,000 people per year in women and 0.8 per $1,000(2)$ in men, with a prevalence of $2 \%$ to $3 \%$ of the population (3). Graves' disease has $1 \%$ to $2 \%$ of prevalence in women and $0.1 \%$ to $0.2 \%$ in men (2). The association of thyroid autoimmune disease with other autoimmune disorders has been demonstrated previously (4-6). There is an increased prevalence of hypothyroidism and subclinical hypothyroidism in patients with celiac disease (CD), $19.2 \%$ and $21.2 \%$, respectively, as described in Brazilian CD patients (7).

$\mathrm{CD}$ is an immune-mediated enteropathy that develops in genetically susceptible individuals in response to the ingestion of wheat gluten and related proteins found in barley and rye. CD is known to occur with a higher prevalence in individuals with certain syndromes and autoimmune disorders, such as Down syndrome, Turner syndrome, type 1 diabetes mellitus, and ATD $(5,8,9)$. Originally, this affection was thought to almost exclusively affect white Europeans, and it is known currently to be distributed worldwide (10). The prevalence of $\mathrm{CD}$ in the Brazilian general population, specifically of Curitiba (Southern region), an area with predominantly European ancestry, is 1:417 (11). In patients with inadequate control of ATD, using high doses of levothyroxine, CD must be evaluated (12). CD can manifest with typical symptoms, such as growth failure, loss of weight, diarrhea, and deficiency of various nutrients, and with atypical symptoms, such as osteoporosis and infertility. However, a majority of patients suffer from subtle, if any, symptoms (13). Untreated CD is associated with other complications, the most severe being malignant lymphoma or cancer of the small intestine (14).

The objective of this study was to determine the prevalence of CD in adults with ATD from the endocrinology outpatient setting in a university hospital in Southern Brazil.

\section{SUBJECTS AND METHODS}

This is a cross-sectional study carried out from the years 2007 to 2011 , including 254 patients previously diagnosed with ATD which were enrolled consecutively. The patients were recruited from the adult endocrinology service at the Clinics Hospital of the Federal University of Paraná. All patients signed a written consent approved by the ethics committee of the hospital (Approval date: July 2, 2007; approval number of the ethics committee: 1458.123/2007-06; CAAE: 0132.0.208.000-07). All patients included had clear evidence of an ATD, including Hashimoto's and Graves' diseases, diagnosed after clinical suspicion. The diagnosis of Hashimoto's thyroiditis was confirmed with high TSH (thyroid stimulating hormone) levels and low free T4 levels, associated with the presence of positive thyroid antibodies, anti-thyroglobulin (Anti-TG), or anti-thyroide peroxidase antibodies (Anti-TPOs). Some patients also presented with heterogeneous echotexture on ultrasound. The diagnosis of Grave's disease was made with suppressed TSH levels, high free T4, associated with ophthalmopathy, or positivity of thyroid-stimulating hormone receptor antibodies (TRABs), or high iodine uptake on scintigraphy. For all patients charts were reviewed for demographic and clinical profile. Also a questionnaire was taken regarding the presence or absence of common gastrointestinal symptoms (abdominal pain, distension, heartburn, diarrhea, and constipation).

Serum samples to screen for IgA anti-endomysial (IgA-EmA) were collected, separated, aliquoted and immediately stored at $-80^{\circ} \mathrm{C}$ until use. All subjects were screened for IgA-EmA according to Volta and cols. (15), using indirect immunofluorescence with cryostatic sections of human umbilical cord as substrate, with initial dilution $1 / 2.5$. Secondary anti-human IgA conjugate antibodies (GMK, Porto Alegre, Brazil) were used in the reactions. Positive samples were tittered up to the end point; positive and negative controls were used for each bath. This test was used due its high sensitivity (95\%) and specificity (100\%) for the diagnosis of CD (15).

The IgA-EmA-positive patients were clinically reevaluated and submitted to upper endoscopy and biopsy of duodenum segments to confirm the diagnosis of CD. Fragments were fixed in formol, drenched in paraffin, and stained using the hematoxylin-eosin technique. Crypt hyperplasia and villous atrophy were classified as partial (PVA) or total (TVA), according to Marsh (16). In Marsh 0 there are normal villi and normal hyperplasia; Marsh 1 shows epithelial cells being infiltrated by lymphocytes; Marsh 2 shows increased lymphocytes and hyperplastic crypts; Marsh 3 has the same changes of Marsh 2 but with villi atrophy (partial: 3a, subtotal: $3 \mathrm{~b}$, total atrophy: $3 \mathrm{c}$ ); Marsh 4 has villi atrophy and shrunken cryps. Marsh $3 \mathrm{~b}, 3 \mathrm{c}$ and 4 are specific for the diagnosis of CD. 
As control group, blood samples from 100 healthy volunteers not related to the patients were used. All of them were students or hospital workers, with no digestive or extra-digestive symptoms, nor thyroid disease, coming from the same geographic area (93\% female, $7 \%$ male, mean age of 42 years, range 19 to 81 years). All had IgA-EmA negative results.

Data were collected in frequency and contingency tables, and statistical analyses were performed with Graph Pad Prism 4.0 (GraphPad Software Inc., La Jolla, USA), using Chi-square and Fisher's tests when indicated. The significance level was set at 0.05 .

\section{RESULTS}

The clinical and demographic characteristics of the studied groups are shown in table 1.

Table 1. Clinical and demographic profile of patients with autoimmune thyroid diseases (ATD)

\begin{tabular}{lcccc}
\hline & Total & $\begin{array}{c}\text { Hashimoto's } \\
\text { disease } \\
(\mathbf{n = 1 1 1})\end{array}$ & $\begin{array}{c}\text { Grave's } \\
\text { disease } \\
\mathbf{( n = 1 4 3 )}\end{array}$ & $\begin{array}{c}\text { Healthy } \\
\text { control } \\
\mathbf{( n = 1 0 0 )}\end{array}$ \\
\hline Male & $32(12.6 \%)$ & 7 & 25 & 7 \\
Female & $222(87.4 \%)$ & 104 & 118 & 93 \\
Mean age & $45.4 \pm 13.43$ & $45.9 \pm 13.42$ & $44.9 \pm 13.47$ & $42 \pm 15.62$ \\
Range & $(18-79$ years $)$ & $(18-75$ years $)$ & $(18-79$ years $)$ & $(19-81$ years $)$ \\
\hline
\end{tabular}

Most patients were female (87.4\%), with mean age at the time of the inclusion of $45.4 \pm 13.43$ years ( 18 to 79 years). Grave's disease was diagnosed in $143(56.3 \%)$ and Hashimoto's thyroiditis in $111(43.7 \%)$ patients.
IgA-EmA was positive in seven patients $(7 / 254$, $2.7 \%)$. Four of them had Hashimoto's thyroiditis (4/111), and 3 had Graves' disease (3/143), with no significant difference between groups $(\mathrm{p}=0.49)$. The IgA-EmA titers varied from $1: 2.5$ to $1: 40$. Among the seven IgA-EmA positive patients, five were submitted to endoscopy with biopsy. One refused the exam, and one could not have a biopsy because of thrombocytopenia (platelet count less than 150.000 platelets per microliter). Between the five patients submitted to endoscopy, three had the diagnosis of CD confirmed (3/254, $1.2 \%)$. All the three patients with CD had higher IgAEmA titers (1:10, 1:20, and 1:40), were female, and had Hashimoto's thyroiditis.

Among the two IgA-EmA positive patients without confirmed CD in biopsy, one had normal biopsy, and the other had the aspect of atrophic gastritis in endoscopy. In the latter patient, the biopsy of the altered area in the stomach showed autoimmune gastritis. Both had low serum titers of $\operatorname{IgA}$-EmA (1:2.5), as demonstrated in table 2 .

In relation to gastrointestinal symptoms, an increased prevalence of abdominal distention in Graves' disease $(75 / 143)$ and of heartburn in Hashimoto's thyroiditis $(55 / 111)$ was observed. None of the patients diagnosed with $\mathrm{CD}$ or with IgA-EmA positive had a history of diarrhea and like other patients with ATD, these patients had nonspecific gastrointestinal symptoms, such as heartburn and gastric distention (Table 2).

Table 2. Clinical and demographical findings in patients positive to antiendomysial antibodies

\begin{tabular}{|c|c|c|c|c|c|c|c|}
\hline Case & Diagnosis & Age & Gender & EmA-IgA & Symptoms & Other AID & Endoscopy/Biopsy* \\
\hline 1 & Hashimoto's disease & 33 & $\mathrm{~F}$ & $1: 20$ & Heartburn & No & $\begin{array}{l}\text { Celiac disease } \\
\text { Marsh Illb }\end{array}$ \\
\hline 2 & Grave's disease & 59 & $\mathrm{~F}$ & $1: 2.5$ & $\begin{array}{l}\text { Abdominal pain and distention, } \\
\text { articular pain, anemia }\end{array}$ & Vitiligo & $\begin{array}{l}\text { Biopsy not possible due to } \\
\text { plaquetopenia }\end{array}$ \\
\hline 3 & Hashimoto's disease & 64 & M & $1: 2.5$ & $\begin{array}{l}\text { Abdominal pain and distention, } \\
\text { heartburn, constipation, } \\
\text { articular pain }\end{array}$ & Psoriasis & Normal \\
\hline 4 & Grave's disease & 79 & $\mathrm{~F}$ & $1: 2.5$ & Anemia, depression & No & Autoimmune gastritis \\
\hline 5 & Hashimoto's disease & 19 & $\mathrm{~F}$ & $1: 40$ & $\begin{array}{l}\text { Abdominal pain and distention, } \\
\text { heartburn, constipation }\end{array}$ & No & $\begin{array}{c}\text { Celiac disease } \\
\text { Marsh IV }\end{array}$ \\
\hline 6 & Hashimoto's disease & 43 & $F$ & $1: 10$ & $\begin{array}{l}\text { Abdominal pain and distention, } \\
\text { heartburn, articular pain }\end{array}$ & No & $\begin{array}{l}\text { Celiac disease } \\
\text { Marsh IIIb }\end{array}$ \\
\hline 7 & Grave's disease & 32 & $\mathrm{~F}$ & $1: 2.5$ & No symptoms & No & Refused endoscopy \\
\hline
\end{tabular}

EmA-IgA: antiendomisial antibodies; AID: autoimmune disease.

* Marsh Classification. 


\section{DISCUSSION}

In the present study, the screening done detected a prevalence of $1: 36(7 / 254) \operatorname{IgA}-E m A$ positive tests among patients with autoimmune thyroid disease (ATD), and one in each 85 patients $(3 / 254)$ confirmed the diagnosis of CD by endoscopy and biopsy, compared with 1:417 people in the general population in Southern Brazil (11).

Our hospital is a tertiary hospital and treats more complex diseases. Therefore, despite the higher prevalence of Hashimoto thyroiditis in the general population in comparison with Graves' disease, our sample had even more Graves' than Hashimoto's disease ( $56.3 \%$ versus $43.7 \%$, respectively).

The importance of screening for autoimmune thyroid diseases in patients with celiac disease and for other autoimmune disorders, independent of age of diagnosis of $\mathrm{CD}$, had already been demonstrated. Fifty-two patients with celiac disease in the same area of our study, in Southern Brazil, were studied for thyroid disorders. Kotze and cols., demonstrated an increased prevalence of hypothyroidism (19.2\%) and subclinical hypothyroidism $(21.2 \%)$ in $\mathrm{CD}$ patients, even on gluten-free $\operatorname{diet}(\mathrm{GFD})(7)$.

Sattar and cols. (4) showed a higher prevalence of CD in patients with ATD: $4.6 \%$ of subjects with ATD had positive $\operatorname{IgA}-\mathrm{EmA}$, and the occurrence of biopsyconfirmed CD was $2.3 \%$. However, this study included patients with Down syndrome and type-1 diabetes. CD is associated with Down and Turner syndromes and other conditions that have autoimmune features, such as type-1 diabetes mellitus $(17,18)$. When Sattar and cols., excluded patients with type-1 diabetes and Down syndrome, there was no higher prevalence of CD compared with the general population. Nisihara and cols., investigated children with Down syndrome from the same area of Brazil and showed a high prevalence of confirmed CD $(5.6 \%)(18)$. Our sample with ATD patients had a higher prevalence of IgA-EmA than the control group and a higher prevalence of CD than the general population, and there were no cases of type- 1 diabetes and Turner or Down syndrome among the evaluated individuals.

Mehrdad and cols. (19), did not show a higher prevalence of CD in patients with hypothyroidism in an Iranian population, although their data disagree with those of various other authors $(5,6,20)$.

The literature shows that the absorption of levothyroxine (T4) can be impaired with $\mathrm{CD}$ and that GFD can improve hypothyroidism and reduce levothyroxine dosage. The therapeutic dosage of $\mathrm{T} 4 \mathrm{can}$ increase up to $50 \%$ in untreated CD patients. This fact can be explained by mucosal damage or presence of undigested food and a net increase of water in the intestinal lumen. Partial recovery of mucosal structure may be sufficient to improve $\mathrm{T} 4$ absorption $(21,22)$. In this context, one patient of our study with confirmed diagnosis of CD, which has been treated by the gastroenterology service of our hospital, had a reduction in the dosage of levothyroxine from 175 to $125 \mathrm{mcg}$, with a better control of the hypothyroidism, approximately one year after the initiation of a GFD.

CD should be suspected by general physicians and endocrinologists in patients with osteoporosis, infertility, or other autoimmune disorders (14). In the present study, patients with ATD and concomitant CD did not have typical symptoms, which include chronic diarrhea, loss of weight, or anemia, and this can occur in a high percentage of cases (22). Our patients had most commonly gastric distention and heartburn that represent gastrointestinal symptoms seen in the general population. However, regardless of symptoms, untreated CD is associated with malignant lymphoma or cancer of the small intestine (14) and, therefore, should always be considered in patients at risk, including patients with ATD.

Compared with our former study (7) in patients from the same geographic area, we found that ATD patients are less commonly affected with $\mathrm{CD}$ than $\mathrm{CD}$ patients with ATD.

This study presents some limitations as impossibility of duodenal biopsy in all patients IgA-EmA positive and lack of data on bone densitometry. Also, the authors had some difficulties in the patient's follow-up due to lack of data when this patient was attended in the gastroenterology service.

In conclusion, we found a prevalence of $1.2 \%$ (1:85) of confirmed CD among Brazilian patients with ATD. Although some IgA-EmA positive patients had Graves' disease and one was male, all three patients with confirmed CD were female and had Hashimoto's thyroiditis.

Source of funding: none.

Disclosure: no potential conflict of interest relevant to this article was reported.

\section{REFERENCES}

1. Gessl A, Lemmens-Gruber R, Kautzky-Willer A. Thyroid disorders. Handb Exp Pharmacol. 2012;(214):361-86. 
2. Hollowell JG, Staehling NW, Flanders WD, Hannon WH, Gunter EW, Spencer CA, et al. Serum TSH, T(4), and thyroid antibodies in the United States population (1988 to 1994): National Health and Nutrition Examination Survey (NHANES III). J Clin Endocrinol Metab. 2002;87(2):489-99.

3. Sgarbi JA, Maciel RM. Pathogenesis of autoimmune thyroid diseases. Arq Bras Endocrinol Metabol. 2009;53(1):5-14.

4. Sattar N, Lazare F, Kacer M, Aguayo-Figueroa L, Desikan V, Garcia $\mathrm{M}$, et al. Celiac disease in children, adolescents, and young adults with autoimmune thyroid disease. J Pediatr. 2011;158(2):272-5.

5. Chang CL, Jones MK, Kingham JGC. Celiac disease and autoimmune thyroid disease. Clin Med Res. 2007;5(3):184-92.

6. Boelaert K, Newby PR, Simmonds MJ, Holder RL, Carr-Smith JD, Heward JM, et al. Prevalence and relative risk of other autoimmune diseases in subjects with autoimmune thyroid disease. Am J Med. 2010;123(2):183.

7. da Silva Kotze LM, Nisihara RM, da Rosa Utiyama SR, Piovezan GC, Kotze LR. Thyroid disorders in Brazilian patients with celiac disease. J Clin Gastroenterol. 2006;40(1):33-6.

8. Ch'ng CL, Biswas M, Benton A, Jones MK, Kingham JG. Prospective screening for coeliac disease in patients with Graves' hyperthyroidism using anti-gliadin and tissue transglutaminase antibodies. Clin Endocrinol (Oxf). 2005;62(3):303-6.

9. Hadithi $M$, de Boer $H$, Meijer JW, Willekens F, Kerckhaert $J A$, Heijmans $R$, et al. Coeliac disease in Dutch patients with Hashimoto's thyroiditis and vice versa. World J Gastroenterol. 2007;13(11):1715-22.

10. Fasano A, Catassi C. Current approaches to diagnosis and treatment of celiac disease: an evolving spectrum. Gastroenterology. 2001;120(3):636-51.

11. Pereira MA, Ortiz-Agostinho $C L$, Nishitokukado I, Sato $M N$, Damião $\mathrm{AO}$, Alencar ML, et al. Prevalence of celiac disease in an urban area of Brazil with predominantly European ancestry. World J Gastroenterol. 2006;12(40):6546-50.
12. Collin P, Kaukinen K, Välimäki M, Salmi J. Endocrinological disorders and celiac disease. Endocr Rev. 2002;23(4):464-83.

13. Chand N, Mihas AA. Celiac disease: current concepts in diagnosis and treatment. J Clin Gastroenterol. 2006;40(1):3-14.

14. Collin $P$, Huhtala $H$, Virta $L$, Kekkonen $L$, Reunala T. Diagnosis of celiac disease in clinical practice: physician's alertness to the condition essential. J Clin Gastroenterol. 2007;41(2):152-6.

15. Volta U, Molinaro N, de Franceschi L, Fratangelo D, Bianchi FB. IgA anti-endomysial antibodies on human umbilical cord tissue for celiac disease screening. Save both money and monkeys. Dig Dis Sci. 1995;40(9):1902-5.

16. Marsh MN. Gluten, major histocompatibility complex, and the small intestine. A molecular and immunobiologic approach to the spectrum of gluten sensitivity ('celiac sprue'). Gastroenterology. 1992;102:330-54.

17. Holmes GK. Coeliac disease and type 1 diabetes mellitus - the case for screening. Diabet Med. 2001;18(3):169-77.

18. Nisihara RM, Kotze LM, Utiyama SR, Oliveira NP, Fiedler PT, Messias-Reason IT. Celiac disease in children and adolescents with Down syndrome. J Pediatr (Rio J). 2005;81(5):373-6.

19. Mehrdad M, Mansour-Ghanaei F, Mohammadi F, Joukar F, Dodangeh S, Mansour-Ghanaei R. Frequency of celiac disease in patients with hypothyroidism. JThyroid Res. 2012;2015:38.

20. Spadaccino AC, Basso D, Chiarelli S, Albergoni MP, D'Odorico A, Plebani M, at al. Celiac disease in North Italian patients with autoimmune thyroid diseases. Autoimmunity. 2008;41(1):116-21.

21. Jiskra J, Límanová Z, Vanícková Z, Kocna P. IgA and IgG antigliadin, IgA anti-tissue transglutaminase and antiendomysial antibodies in patients with autoimmune thyroid diseases and their relationship to thyroidal replacement therapy. Physiol Res. 2003;52(1):79-88.

22. Virili C, Bassotti G, Santaguida MG, luorio R, Del Duca SC, Mercuri $\mathrm{V}$, et al. Atypical celiac disease as cause of increased need for thyroxine: a systematic study. J Clin Endocrinol Metab. 2012;97(3):E419-22. 